\title{
Árbol en gemación
}

\section{Tree in bud}

Ana Manzano, MD.(1), Carlos Celis Preciado, MD.(2)

Este patrón escanográfico consiste en opacidades ramificadas, usualmente localizadas en la periferia del pulmón, cuyo aspecto recuerda las yemas de las ramas de un árbol (figura 1). Su aspecto típico es el de opacidades ramificadas, con extremos bulbosos, localizadas a pocos milimetros de la pleura (figura 2) (1-4).

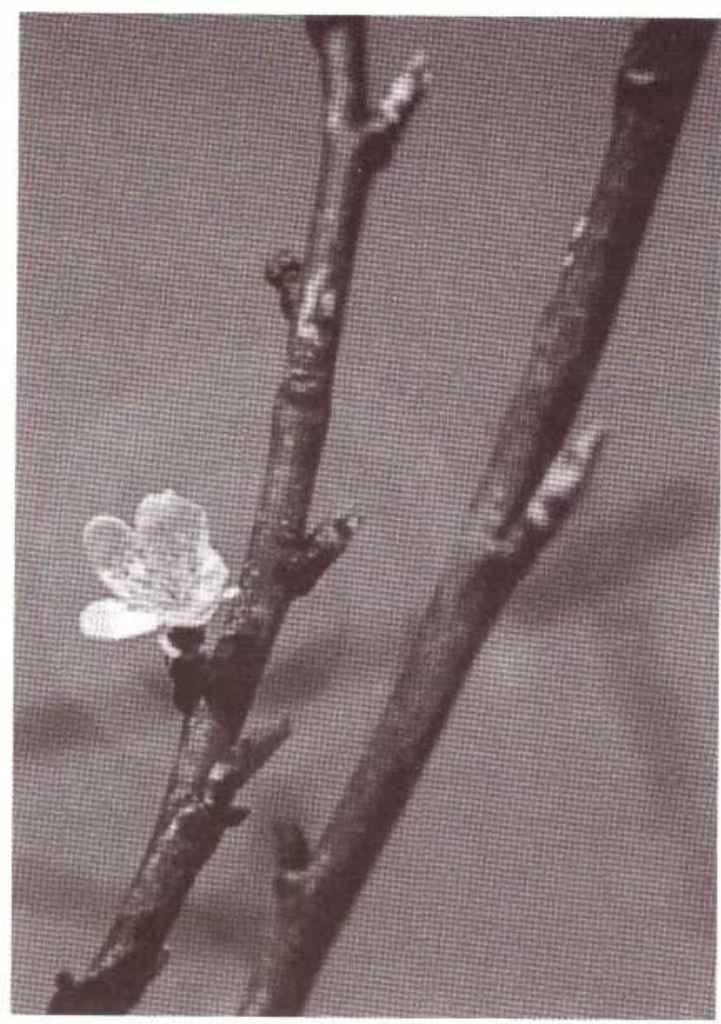

Figura 1. Árbol en gemación.
Representa la dilatación de bronquiolos centrilobulillares (bronquiolectasias) con impactación de su luz con líquido, moco, pus o sangre (figura 3). Generalmente se asocia con inflamación peribronquiolar y con frecuencia nódulos del espacio aéreo y áreas de consolidación (1-4).

Okada y cols. en 553 pacientes con nódulos centrilobulillares, demostraron que el patrón de árbol en gemación era una bronquiolitis infecciosa en casi todos los pacientes, excepto en aquellos con panbronquiolitis difusa y con bronquiolitis aspirativa difusa, que también característicamente cursan con este hallazgo (5).

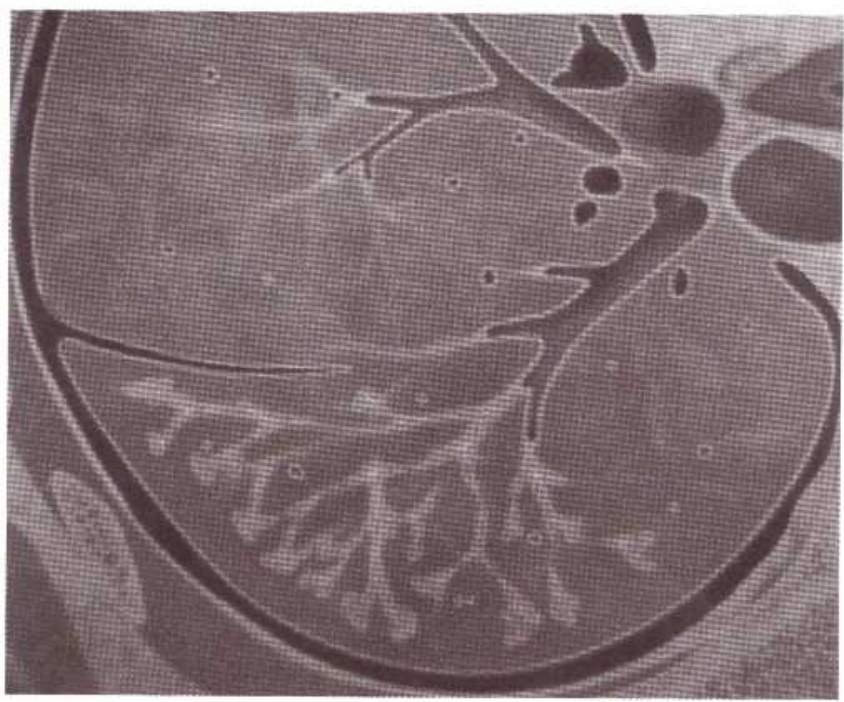

Figura 2. Ilustración que muestra el patrón de árbol en gemación.

\footnotetext{
(1) Radióloga. Departamento de Radiología, Hospital Universitario San Ignacio, Pontificia Universidad Javeriana. Bogotá, Colombia.

(2) Internista, Neumólogo. Unidad de Neumologia, Departamento de Medicina Interna, Hospital Universitario San Ignacio, Pontificia Universidad Javeriana. Bogotá, Colombia.
}

Correspondencia: Doctora Ana Manzano. Correo electrónico: crispetamanzano@gmail.com

Recibido: diciembre 6 de 2012. Aceptado: diciembre 21 de 2012. 


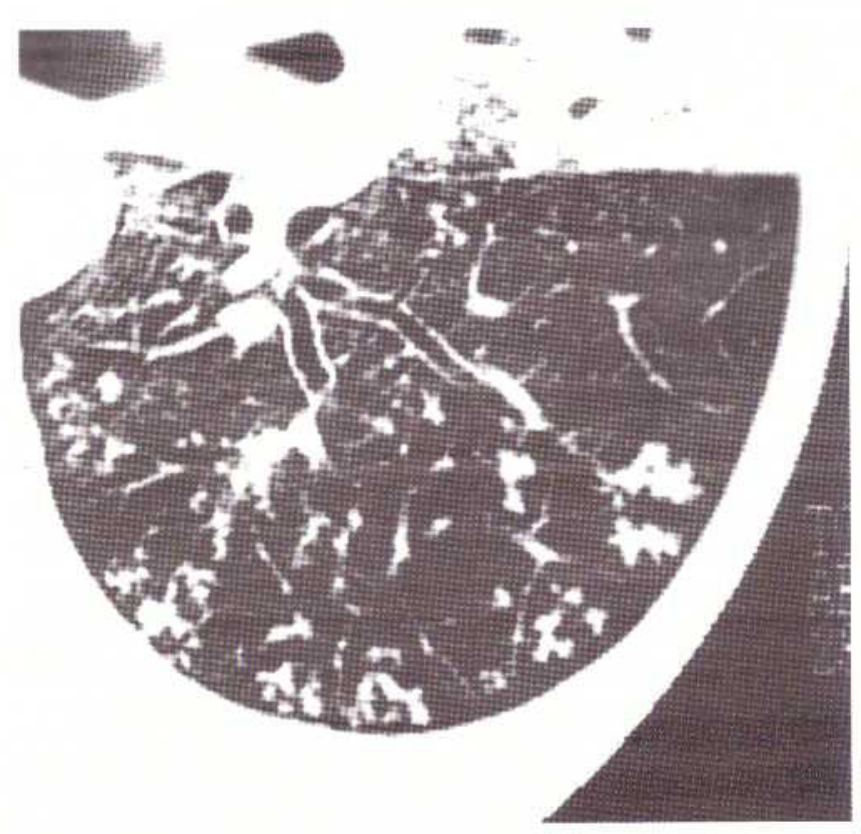

Figura 3. TACAR de tórax con opacidades ramificadas en patrón de árbol en gemación.

De igual manera, los investigadores señalaron que la contundente mayoría de nódulos centrilobulillares de otro tipo tienen una etiologia no infecciosa (5). Las causas principales de patrón de árbol en gemación son procesos infecciosos que involucran la pequeña vía aérea: bronquiolitis infecciosas bacterianas, tuberculosis, bronconeumonía bacteriana, bronquiectasias sobreinfectadas, micobacterias atipicas, infecciones virales, fibrosis quistica, asma y aspergilosis broncopulmonar alérgica (7-9).

Otras causas menos frecuentes, que representan patologias que ocasionan bronquiolectasias impactadas son: bronquiolitis folicular, carcinoma bronquioloalveolar y neumonitis aspirativa difusa (tabla) (2-9).

\section{BIBLIOGRAFÍA}

1- Fleishner Society: Glossary of Terms For Thoracic Imaging. Radiology 2008; 46: 697-722.

2- Verma N, Chung JH, Mohammed TL. "Tree-in-bud sign". J Thorac Imaging. 2012; 27: W27.
Tabla. Causas de patrón escanográfico de árbol en gemación.

\begin{tabular}{|l|}
\hline Infecciosas \\
\hline Bronconeumonia bacteriana \\
Tuberculosis \\
Micobacterias no tuberculosas \\
Mycoplasma pneumoniae, Staphylococcus aureus, \\
Haemophilus influenzae \\
Citomegalovirus \\
Virus sincitial respiratorio \\
\hline Inmunológicas \\
\hline Aspergilosis broncopulmonar alérgica \\
Sarcoidosis \\
\hline Neoplásicas \\
\hline Carcinoma bronquioloalveolar, linfoma, microangiopa- \\
tia trombótica \\
\hline Enfermedades del tejido conectivo \\
\hline Artritis reumatoide \\
Síndrome de Sjögren \\
\hline Congénitas \\
\hline Fibrosis quistica \\
Síndrome de cilia inmóvil \\
\hline Otras \\
\hline Aspiración \\
Bronbronquiolitis difusa \\
\hline
\end{tabular}

3- Saxena AK, Mittal V, Sodhi KS. Tree-in-bud pattern: spectrum of cause. AJR Am J Roentgenol. 2010; 195: W313.

4- Eisenhuber E. The tree-in-bud sign. Radiology. 2002; 222: 771 2.

5- Okada F. et al. Clinical/Patholigic Correlation in 553 Patients with Primary Centrilobular Findings on High Resolution CT of the Lung. Chest 2007; 132; 1939-1948.

6- Rossi SE, Franquet T, Volpacchio M, Giménez A, Aguilar G. Tree-in-bud pattern at thin-section CT of the lungs: radiologicpathologic overview. Radiographics. 2005; 25: 789-801.

7- Reitner,P. et al: Mycoplasma Pneeumoniae Pneumonia: Radiographic and High Resolution CT Features in 28 Patients. AJR 2000; 174: 37-41.

8- Burril J. et al. Tuberculosis: a Radiologic Review. Radiographics. 2007; 27: 1255-1273.

9- Devaconda A, Raoof S, Sung A, Travis W, Naidich D. Bronchiolar Disorders: a Clinical-Radiological Diagnostic Algorithm. Chest 2010; 137: 938-951. 